Chapter 5

\title{
Excavation \& Conservation of Fossils from the Baynunah Formation
}

\author{
Marilyn Fox \\ Yale Peabody Museum of Natural History, 170 Whitney Avenue, New Haven CT 06511, USA \\ marilyn.fox@yale.edu
}

\begin{abstract}
The recovery, preparation, and conservation of fossil remains found in the late Miocene Baynunah Formation, Abu Dhabi, present special challenges. In this chapter, field experiences are covered, and solutions are proposed for some of the challenges for the recovery and conservation of fossils in this sandy desert environment. This chapter provides paleontologists and those concerned with Abu Dhabi's fossil heritage, whether in the field or the laboratory, with suggestions for best practices in the collection, preparation, molding and casting, and long-term conservation of this evidence of past life.
\end{abstract}

Running head: Excavation \& conservation 


\section{Introduction}

What do we mean by excavation and conservation? When fossils are discovered, we aim to retrieve the greatest amount of scientific information possible from the specimens. This requires bringing fossils safely to a controlled environment, such as a preparation laboratory, where they can be prepared and made available for research. To do this, we must first carefully expose the bone in the field, in the sun and the wind, sometimes while sliding down hillsides, so that we can recover the entirety of the specimen. We then apply adhesives and wrapping to hold the bones together until they reach the laboratory. There, fragile bones can be removed from the enclosing rock or sand (matrix) under controlled conditions. Preparation and conservation of fossil material requires specialized skills and knowledge, and is not to be undertaken lightly. At any point, it is possible to damage or destroy the specimen and lose crucial information about past life that it contains. Trained in field excavation techniques and micro-excavation within the lab, the fossil preparator works to expose the information contained within a fossil. Once a fossil is prepared, it must be preserved for future research, with proper support and storage.

Fossils of the Baynunah Formation are recovered from an area $\sim 200 \mathrm{~km}$ long and stretching from the coast to $\sim 50 \mathrm{~km}$ inland (Bibi et al. this volume). The hot, humid, and sandy environments of western Abu Dhabi Emirate create challenges not just for the discovery of fossils, but for their recovery as well. Fluctuating temperature and humidity induces fossils to expand and crack even before they have reached the surface, while a layer of wind-blown sand hides them from view. Desert gypsum often covers bony surfaces, while salts dissolved in the bone structure can continue to deform the shape of fossils even years after they have been removed from the ground. This chapter aims to present some of the basic collection methodologies used in the recovery of vertebrate fossils from the Baynunah Formation, 
particularly large specimens needing excavation and careful removal.

FIGURE 5.1 ABOUT HERE; WIDTH = 2 COLUMNS

\section{Discovery \& Excavation}

A primary goal of field collection is the preservation of as much information contained with the specimen at the moment of discovery as possible. Before any excavation takes place, pertinent data about the site is collected. This includes locational and geological (stratigraphic) description, site and specimen photos, and Global Positioning System (GPS) latitude, longitude, and altitude readings. All of this data is necessary to be able to describe the specimen in relation to its geological setting (age) depositional environment, taphonomy, relationship to other specimens, and for future researchers to be able to relocate the exact site.

Several approaches are used in the discovery and recovery of fossils from the Baynunah Formation. One method used for collecting very small specimens is dry screening. As seen in Fig. 5.1c, matrix (sand and rock) from the site is placed on a screen, gently shaken to remove smaller particles, and then examined carefully. This method allows for the recovery of the tiniest vertebrate fossil remains, such as the rodent tooth seen in Fig. 5.1d. In the Baynunah Formation, sediment was successively sieved through 4-, 1.3-, and 0.6-mm sieves, and then sorted grain-bygrain (Kraatz et al. 2013; Kraatz this volume). Most small fossils were found in the $1.3 \mathrm{~mm}$ sort.

The primary method by which fossils were recovered in the Baynunah, however, is surface collection. This involves systematically surveying hill slopes, gullies, and other outcrop exposures on foot, searching for fragments of fossilized bone eroding out of the surface sands. In most instances, fossil bone has been lying at or close to the surface for months, years, or decades 
before it is discovered. Exposure to wind, evaporative salts, and rain results in breakage and leaves bones fragile. Additionally, many of the collecting areas in the Baynunah are close to areas of human habitation or activity, and damage due to human disturbance is not uncommon. Surface fossils as found in the field are fragile and specimens must be protected and supported until these can be prepared in the laboratory under controlled conditions. When a specimen requires excavation, the first step, after recording pertinent site data, is to carefully explore around the exposed bone to find the edges of the specimen. Initial matrix (sediment) removal at these sites is done primarily with soft brushes, as the fossils usually sit in loose superficial sand. Other tools often used are small curved art knives (e.g. X-Acto with \#11 blades) and sharpened drill blanks, for delicate matrix removal near the specimen. Very little of the bone is actually exposed in the field, and enough matrix is retained to hold fragmented specimens together.

After the bones start to be exposed they are often consolidated. A thin solution of adhesive is applied to hold all the fragmented pieces together. A preparator's knowledge and experience with the range of adhesives available enables them to choose the best adhesive for each situation. In our case, the primary adhesive used was Butvar B-76, a polyvinyl butyral, mixed at $5 \% \mathrm{w} / \mathrm{w}$ in acetone. This adhesive remains soluble in ethanol or acetone, so that it can be easily softened in the lab and excess matrix can later be removed. Most preparators tend not to favor consolidation in the field unless absolutely necessary, as it can adhere excess matrix and make later preparation more complicated.

In some fossil collecting areas, fossils are excavated from harder rocks like mudstones or siltstones or even cemented conglomerates; this makes the actual process of excavation physically more challenging than when working in soft and loose sand. However, loose sand can make keeping small bits of bone together, even after consolidation, quite a challenge. Often an 
enclosing 'jacket' is created using plaster bandages, similar to the ones that are used to support broken human bones. In the jacketing process, the bone is first covered with a protective padding of dampened tissue paper, which forms a barrier between the bone and the plaster. Then several layers of plaster bandage - gauze fabric impregnated with plaster of Paris - are applied. To use, the bandage is dipped in water and tightly form-fit to the contours of the bone. When dry, this forms a hard protective shell for the fragile specimen. The setting of plaster is an exothermic chemical reaction, caused by water activating calcined gypsum. However, even when fully set, plaster of Paris jackets must still dry thoroughly. The coastal sites of Abu Dhabi can be quite humid, and this slows plaster drying times significantly. When set, plaster of Paris is hard and durable, such that jacketed specimens can be safely returned to the lab for preparation under controlled conditions. Once the top of the specimen has been jacketed, the collector can begin to trench downward to create a small pedestal. The specimen can then be flipped over, excess matrix can be cut away and the process repeated on the other side, until the delicate bones are safely encased.

\section{PLACE FIGURE 5.2 ABOUT HERE; WIDTH = 2 COLUMNS}

With larger specimens or specimens that consist of multiple bones, jackets need to be even stronger and more supportive. Such jackets are usually made from burlap, a coarse woven fabric, and plaster of Paris, rather than the lighter medical plaster bandages. These materials, sometimes with extra wooden or metal supports built in, as in Fig. 5.3c, provide the added strength needed to safely transport jackets that might weigh a hundred kilograms or more. A large jacket weighing almost $135 \mathrm{~kg}(300 \mathrm{lbs})$ is not unusual. 
Large fossils, like the lower jaws of the elephant Stegotetrabelodon, shown in Fig. 5.3a-d, go through the same process of excavation in order to expose the edges, consolidation, jacketing, flipping, and jacketing on the reverse side. In the soft sands of the Baynunah, this process can be particularly perilous as the sand pedestal underneath specimens could give way in the midst of jacketing, causing the whole specimen to slump into the sand. This could lead to the fragile fossil falling completely out of the unfinished jacket being constructed to support it. The preparator needs to plan ahead for this and sometimes come up with creative solutions.

\section{PLACE FIGURE 5.3 ABOUT HERE; WIDTH = 2 COLUMNS}

One method is to include more matrix beneath the specimen than would normally be desired, as in Fig. 5.4a. After the jacket has been flipped, this extra matrix can be removed. This method only works with smaller jackets or for well-preserved single bones of medium size. It would not work for a large or disarticulated specimen. In the case of the elephant jaws shown in Fig. 5.3, extra sticks were used to prevent movement of the specimen, which was lying in the ground at an angle. However, this approach could not be used for the collection of a small crocodile skeleton (Fig. 5.4). This specimen was highly disarticulated, fragile, and embedded in siltstone, and as a result had to be removed in a large but narrow block. Special sharpened wooden stakes about $0.75 \mathrm{~m}$ ( 2.5 feet) long were created. Collars were made by cutting $15 \mathrm{~cm}$ ( 6 inches) long PVC pipe pieces that were fitted over the end of each stake and held in place with pipe clamps. The PVC pieces were included in the jacket, creating 'legs' for the jacketed specimen. With this support, it was then possible to gradually undercut and wrap the specimen in plaster bandages in successive stages. After jacketing its top and sides, plaster of Paris and 
burlap were thoroughly wrapped beneath the specimen before it was flipped over. Once the jacket was complete enough, the legs were easily removed by pulling them back up through the collars (Fox et al, 2008).

\section{PLACE FIGURE 5.4 ABOUT HERE; WIDTH = 2 COLUMNS}

\section{Molding fossils in situ}

Sometimes fossil remains cannot be extracted from the site. For example, to collect any of the many wonderful elephant trackways found at Mleisa (Bibi et al., 2012) would be impossible. In that case, molds, which reproduce the exact details found in the original, were made of some of the individual tracks. Molds were made by painting many layers of liquid latex rubber. The latex used, Latex 74, is a high solids, low ammonia natural latex rubber, with about $75 \%$ solids. Latex was selected for this project because it requires no measuring, mixing or deairing, as would be necessary with silicone or polyurethane rubbers. It also leaves no chemical or oil residue that could potentially harm the trackways. Burlap, purchased locally, was used for strengthening. The rubber was separated from the rock with dish soap (washing-up detergent) and talcum powder, purchased locally. These products were easily washed away and left no residue on the site. On returning to the preparation laboratory, the molds were cast in Hydrocal plaster, which is stronger than the plaster of Paris used for field jackets. The resulting casts provide a permanent record of the track that can be studied by researchers off-site.

PLACE FIGURE 5.5 ABOUT HERE; WIDTH = 2 COLUMNS

PLACE FIGURE 5.6 ABOUT HERE; WIDTH = 2 COLUMNS 


\section{Conservation (preparation)}

Preparation commences once the specimen has been safely collected and returned to the lab. Preparation is essentially micro-excavation under controlled laboratory conditions. As collected in the field, the information necessary for research is rarely exposed. The role of the preparator is to carefully expose anatomical details, while preserving the specimen for the future. A preparator is a combination of a craftsman, a chemist, and a materials scientist. Most fine preparation is done under microscopes, to see even the smallest detail, and using specialized tools and adhesives. The preparation laboratory contains microscopes, good lighting, a clean work surface, a fume hood, and all the necessary tools. Many preparation tools are pneumatic and run on compressed air, so an in-house air compressor is essential. Preparation can also be very dusty work, so dust collection and disposal is vital for the long-term health of the preparator. Preparation, especially of small or delicate specimens, requires manual skill and a precise eye. On the smallest specimens, like the small rodent tooth seen in Fig. 5.1d, finely pointed steel or carbide needles can be used to remove the sand, grain by grain.

While preparing the fossil, the preparator is always concerned with the long-term preservation of the specimen. To that end, well-tested archival-quality materials are used. Paraloid B-72, an ethyl methacrylate copolymer, was the adhesive chosen for these fossils.

PLACE FIGURE 5.7 ABOUT HERE; WIDTH = 2 COLUMNS

\section{Long-term preservation of specimens}

\section{Support and Storage}


Fossils, although they may appear strong, do not have the internal cohesion of modern bone. Fossils can and do fall apart under their own weight if not properly supported. Hydrocal plaster or polyethylene foam cradles are form-fit to the individual fossils to evenly support the most complex shapes and the heaviest of bones (Fig. 5.8).

PLACE FIGURE 5.8 ABOUT HERE; WIDTH = 2 COLUMNS

\section{Salts, humidity \& temperature control}

Fossils of the Baynunah Formation are high in salts. Salts within fossils can cause extreme degradation if the humidity and temperature at which the specimens are stored are not controlled. Rapid changes in relative humidity can cause the salts to react and expand, which can result in complete destruction of the fossil from the inside out. High temperatures can have the same effect. Outdoor relative humidity in December in Abu Dhabi can be as high as 70\%. Daytime temperatures can rise to over $40^{\circ} \mathrm{C}\left(100^{\circ} \mathrm{F}\right)$. This makes it important that all collected Baynunah fossils should be stored in a humidity and temperature-controlled storage space. It is recommended that temperatures remain below $21^{\circ} \mathrm{C}\left(70^{\circ} \mathrm{F}\right)$. Relative humidity should remain stable at around $50 \%$.

\section{Conclusion}

The fossils of the Baynunah Formation represent a place and time, a landscape, a fauna that can teach us about the past of our planet, as well as about its future. The unique conditions presented by the coastal desert environment of Abu Dhabi provide several challenges to the processes of collection, preparation, and conservation of this region's paleontological heritage. This chapter 
has provided a basic introduction to these processes and how challenges have been dealt with. Through recovering these important fossils, preparing them, and preserving them to the highest standards, we enable research on these important specimens for generations to come.

\section{Acknowledgements}

Thanks to Walter Joyce for encouraging me to begin this adventure, to Jacques Gauthier and the Yale Peabody Museum of Natural History for continued support of our work in Abu Dhabi, to Mark Beech and Faysal Bibi for their ongoing interest and work on the specimens and what they can tell us about past life, and finally to all that I have met and worked with collecting and preparing the fossils of Abu Dhabi. Fieldwork support was provided by the Abu Dhabi Department of Culture and Tourism (formerly the Authority for Cultural and Heritage) and the Yale University Peabody Museum of Natural History.

\section{References}

Bibi, F., Beech, M., Hill., A, \& Kraatz, B. (this volume). Fossil Localities of the Baynunah Formation. In F. Bibi, B. Kraatz, M. Beech, \& A. Hill (eds.) Sands of Time: Late Miocene Fossils from the Baynunah Formation, U.A.E. (pp. xxx). Cham: Springer.

Bibi, F, Kraatz, B, Craig, N, Beech, M., Schuster, M., Hill, A. 2012. Early evidence for complex social structure in Proboscidea from a late Miocene trackway site in the United Arab Emirates, Biology Letters doi: 10.1098/rsbl.2011.1185.

Brown, M, Davidson, A, Fox M., Jabo, S, Smith, M. 2012. Vertebrate paleontological preparation core competencies and training curriculum: Results from the 2012 Austin workshop. Journal of Vertebrate Paleontology 32: 69-70. 
Fox, M., Bibi F., Hill, A. 2008. Jacketing the desert sands. Abstracts of papers, 68th annual meeting, Society of Vertebrate Paleontology, Journal of Vertebrate Paleontology, 28: (3) 80A.

Fox, M., Yarborough, V. 2004. A review of vertebrate fossil support (and storage) systems at the Yale Peabody Museum of Natural History. Abstracts of papers, 64th annual meeting, Society of Vertebrate Paleontology. Journal of Vertebrate Paleontology, 24: (3): 60A.

Kraatz, B. (this volume). Rodents from the Baynunah Formation. In F. Bibi, B. Kraatz, M. Beech, \& A. Hill (eds.) Sands of Time: Late Miocene Fossils from the Baynunah Formation, U.A.E. (pp. xxx). Cham: Springer.

Kraatz, B. P., Bibi, F., Hill, A., \& Beech, M. (2013). A new fossil thryonomyid from the Late Miocene of the United Arab Emirates and the origin of African cane rats. Naturwissenschaften, 100, 437-449. 


\section{Figure Captions}

Fig. 5.1. A, a team member surveys the hillside, eyes to the ground, looking for tiny fragments of fossil bone. B, white bones eroding from the surface of a hill at HMR 5 (13 Dec 2014). C, team members dry-screen matrix at SHU 2-2, a site that has yielded numerous tiny fossils (16 Dec 2014). D, fossil rodent teeth found by screening, on an Emirati dirham coin for scale. (Credits: B: F. Bibi. C: I. Mazzini. D: B. Kraatz.)

Fig. 5.2. Sequence of excavation. A, Butvar B-76 is carefully added with a pipette to consolidate this delicate specimen. B, the white of the plaster bandage caps the fossil bone, and the collector is digging down to create the pedestal. $\mathbf{C}$, the jacket is carefully flipped over, and readied for the second side of the protective jacket. D, once the jacket is finished and dry, pertinent information is written on the sides. The information includes a field number, the identification of the specimen inside and any other information the preparator will need. Note A, B-C, and D are different specimens (AUH 1191, 1146, 1701). (Credits: A, B, D: M. Beech.)

Fig. 5.3. A, sand is carefully brushed away to expose the edges of the bone. B, once the edges of the bone have been discovered, jacketing can begin. $\mathbf{C}$, the finished jacket has pieces of wood incorporated for extra strength, the struts are placed both longwise and crosswise in the jacket. D, the specimen has been prepared in the lab and the teeth are uncovered for study by researchers. (Credits: A-D: M. Beech.)

Fig. 5.4. A, the pedestal is dug deep below the specimen, and is not undercut. Extra matrix is included below the specimen to prevent slumping. The whole structure is flipped over and the 
excess matrix removed. B, extra wooden supports prevent movement of this specimen. $\mathbf{C}$, sand stakes, especially created for this project, immobilize the specimen while it is being jacketed. D, the completed jacket, flipped over, with plaster of Paris, burlap and additional sticks on the second side. The collars could be cut off but this is not necessary. (Credits: A, B: M. Beech)

Fig. 5.5. A, one of the trackways under study. We chose to mold several of the individual prints. B, a barrier layer of dish soap and talcum powder prevent damage to the tracks from the latex rubber. $\mathbf{C}$, the liquid latex rubber needs to be painted on in multiple layers with a brush, each layer must dry before the next can be applied. D, burlap is added to stabilize the mold. (Credits: A-D: M. Beech.)

Fig. 5.6. A, the mold needs an external support of plaster of Paris to maintain its shape, $\mathbf{B}$, the finished mold is ready to take back to the laboratory to be cast in plaster. $\mathbf{C}$, the tracks are cast in plaster. They can be colored to match the original trackway and used for research or display. (Credits: A: M. Beech.)

Fig. 5.7. A, the laboratory at the Yale Peabody Museum has all the necessary tools for preparation of the tiniest fossils. There are several microscopes, compressed air to run tools that are like mini-jackhammers, fume hoods for molding and casting and all the materials needed to protect delicate fossils. $\mathbf{B}$, when the jacket is brought back to the lab it is carefully sawed open. Many times fossils are prepared on the side that was the bottom in the field. That side is less exposed to weathering, and so is often better preserved. $\mathbf{C}$, In the Baynunah Formation, the matrix is usually just soft sand that can be brushed away, but care must be taken to avoid damage 
to delicate bones. D, pointed steel needles are used to uncover the bones of a Miocene crocodile. These bones were particularly delicate, so extra care was needed. (Credits: D: S. Bold.)

Fig. 5.8 A, the specimen shown in Figs. 5.7b and c, completely prepared. However, this fragile fossil will suffer damage if not supported. In this case, a plaster bandage cradle was created to support the delicate bones. B, compactor storage in the Yale Peabody Museum houses dinosaur fossils in climate controlled storage. These fossils, like those from Abu Dhabi, can suffer from high temperatures and high humidity. In this storage they will be available for research for many years to come (Fox and Yarborough 2004). (Credits: A: S. Bold.) 
Fig 5.1

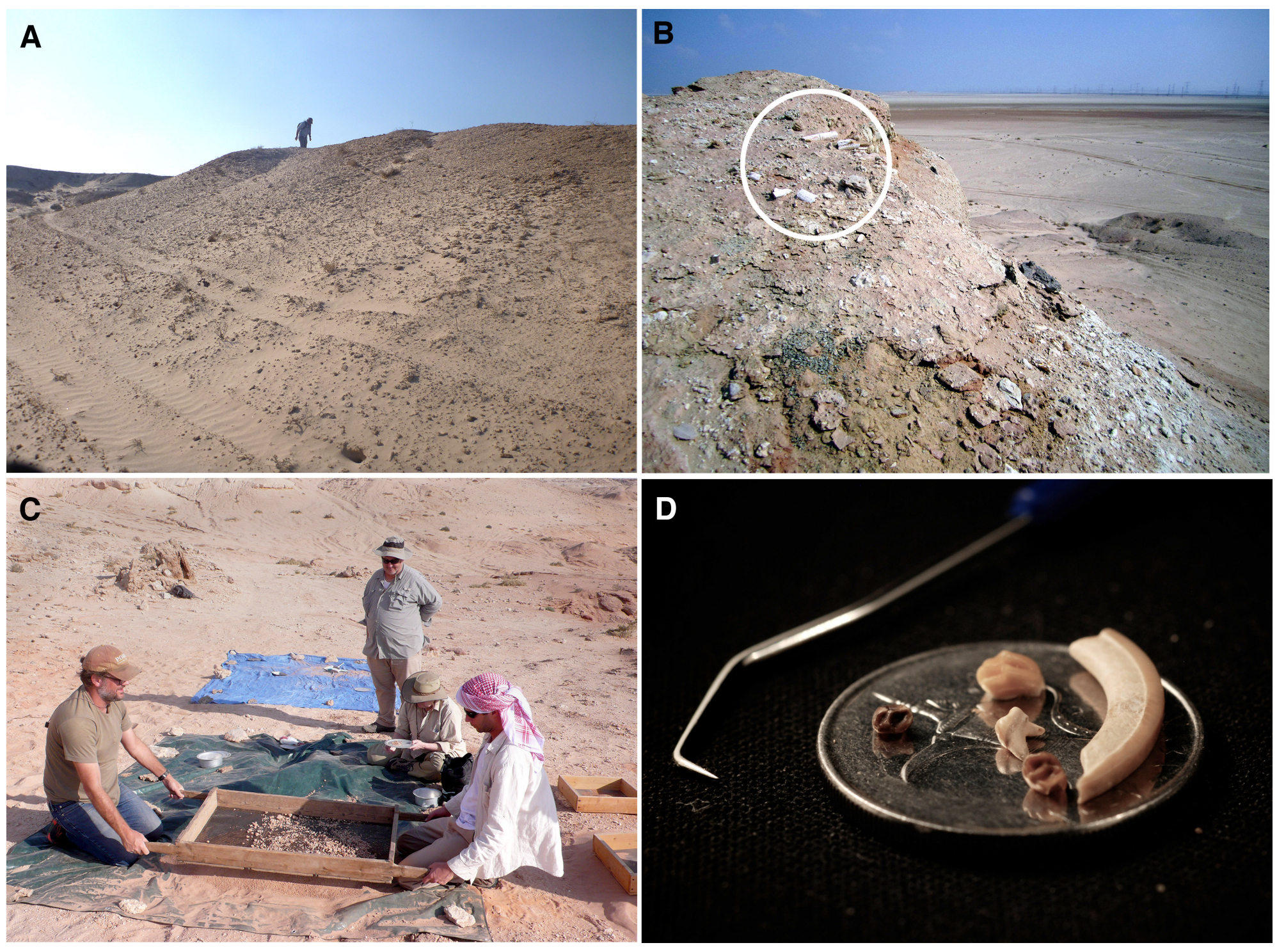


Fig 5.2

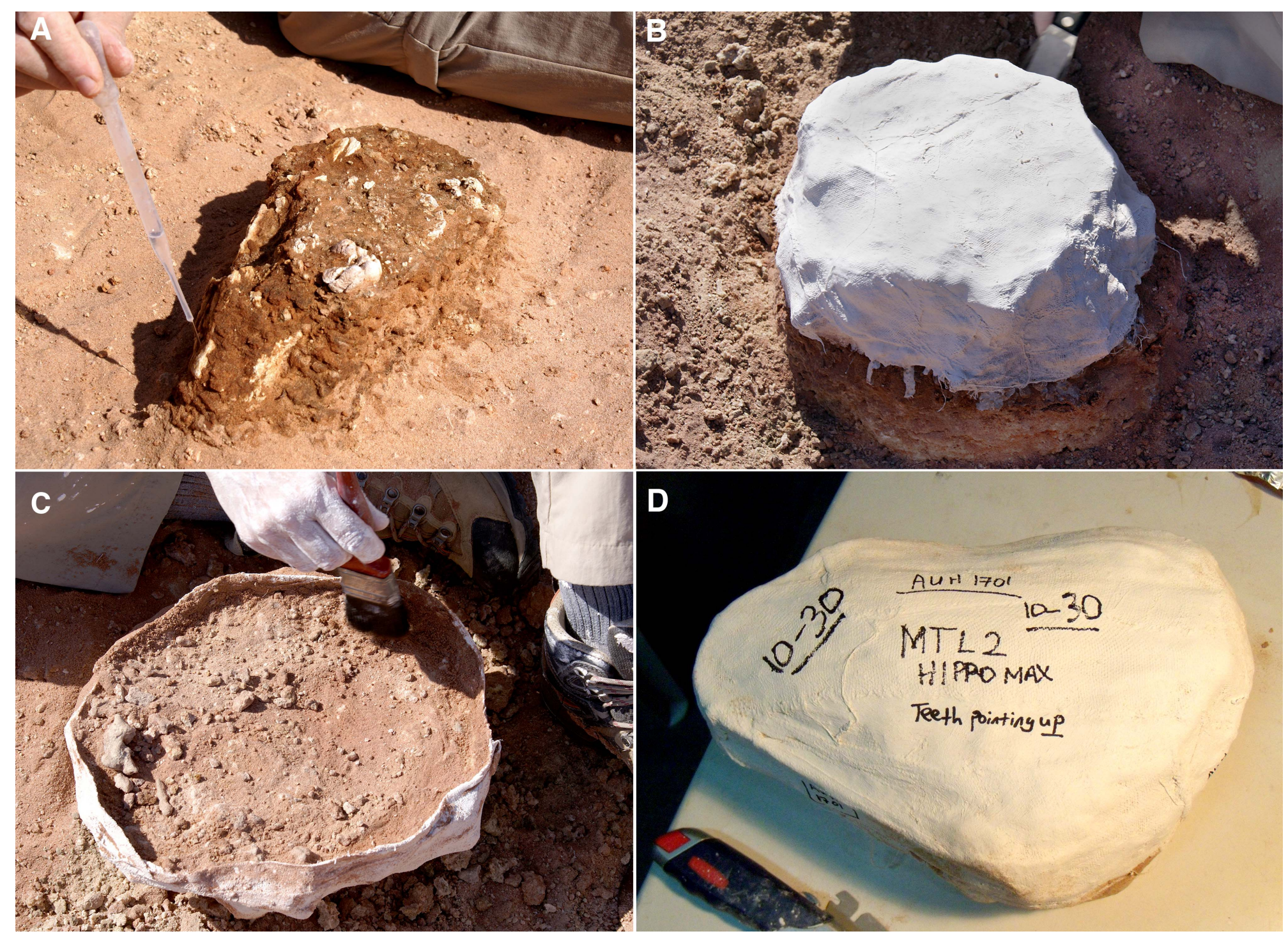


Fig 5.3




Fig 5.4
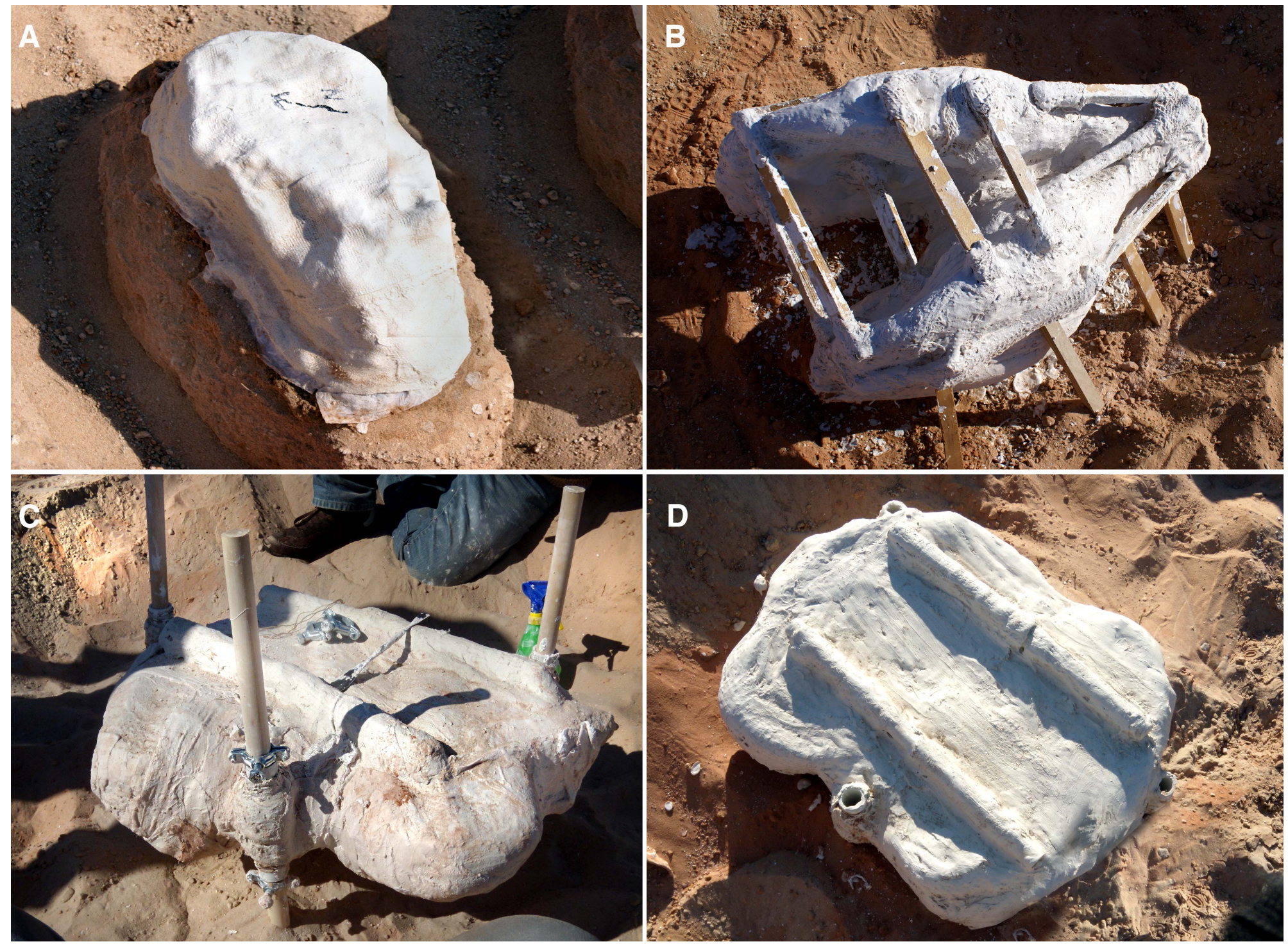
Fig 5.5

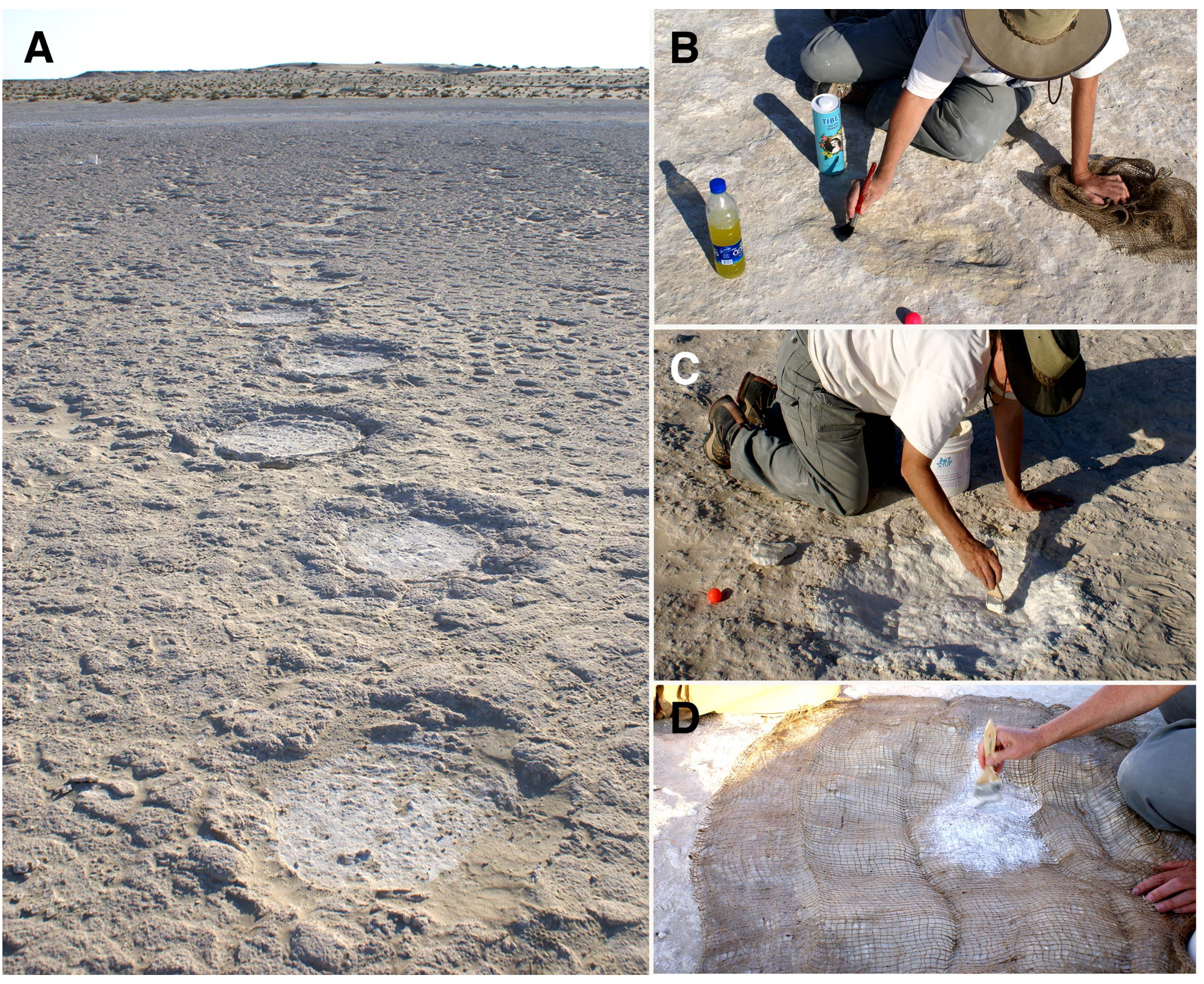


Fig 5.6
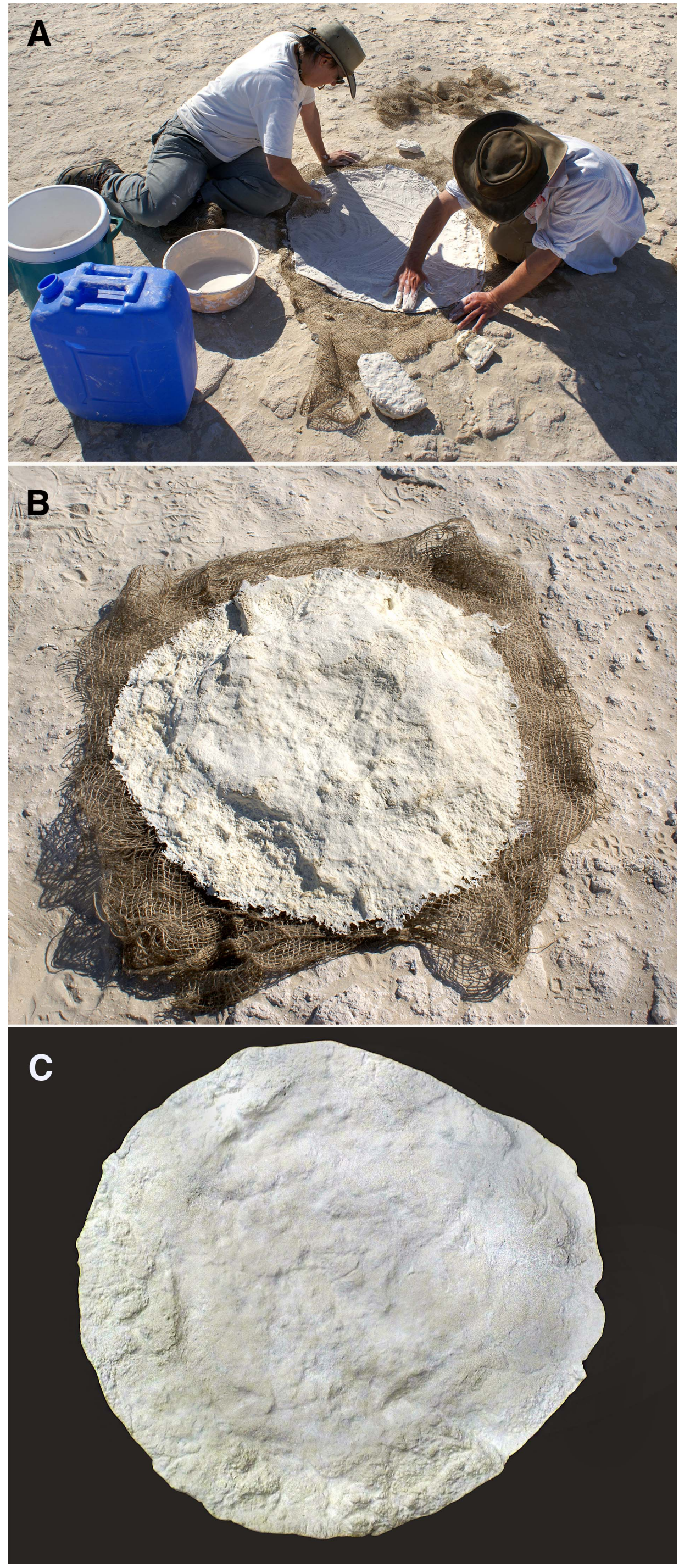
Fig 5.7
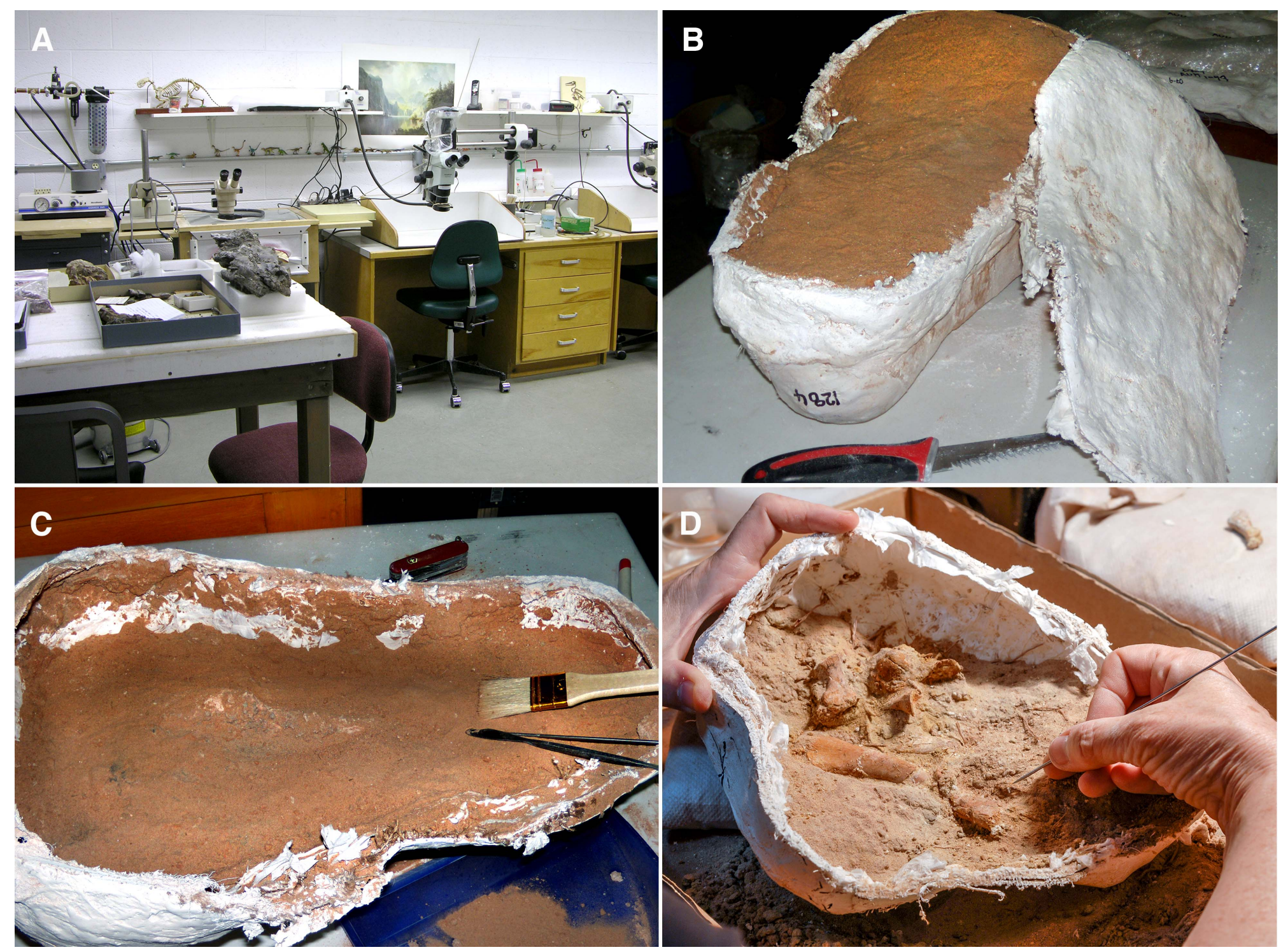

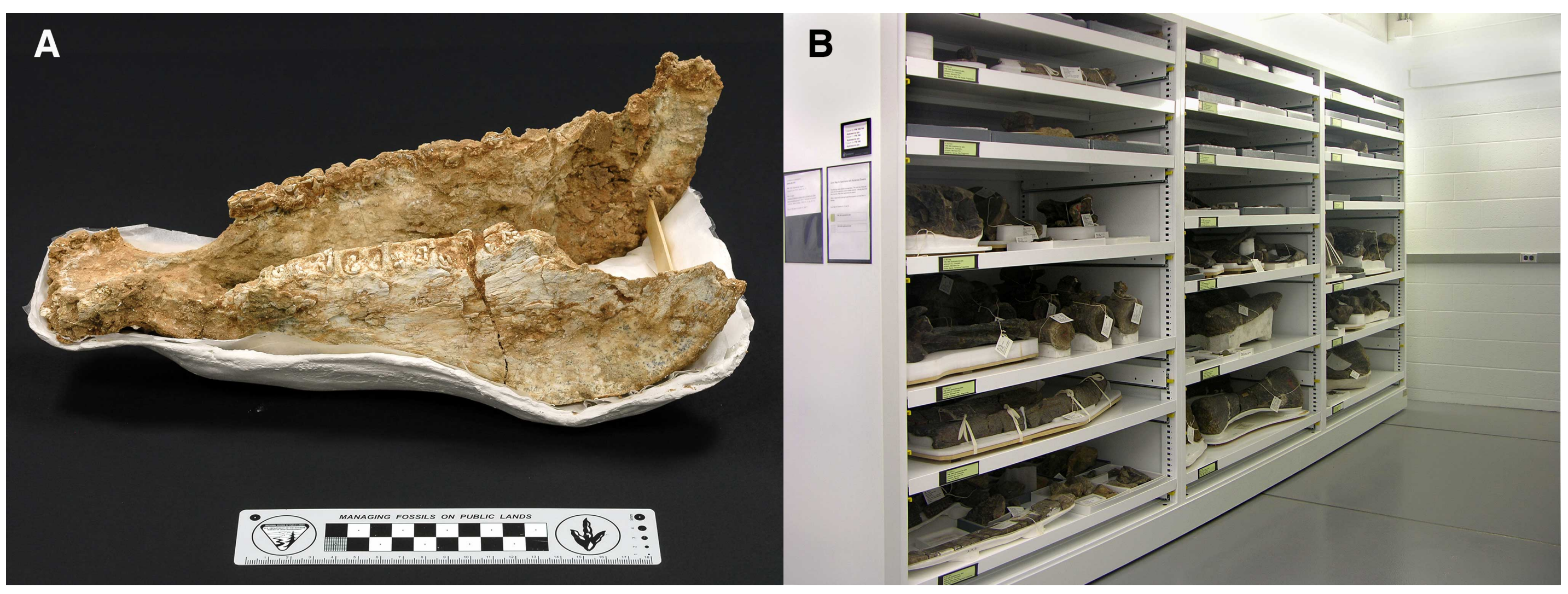